\title{
Keyakinan Agama Dan Gangguan Kesurupan
}

\author{
Siswanto \\ Fakultas Psikologi, Unika Soegijapranata Semarang \\ siswanto@unika.ac.id \\ Subandi \\ Fakultas Psikologi Universitas Gadjah Mada Yogyakarta \\ subandi@ugm.ac.id \\ Ira Paramastri \\ Fakultas Psikologi Universitas Gadjah Mada Yogyakarta \\ ira_paramastri@ugm.ac.id
}

\begin{abstract}
Religious beliefs with possession disorders have not been mentioned much in the scientific literature. This study aims to explore religious beliefs with possession disorders and how to recover. Anthropological literature examines more possessions in terms of culture. On the contrary in the clinical field, it is difficult to find literature that addresses both of these variables. The method used is a case study with semi-structured interviews for data collection. Criteria for participants are having experienced a possession disorder by PPDGJ III at least twice. Six participants met the criteria, all women. Research indicates a link between religious beliefs and possession disorders, both related to their emergence to their recovery efforts. Possession disorder occurs when the belief that there is a spirit is accompanied by the fear that cannot be controlled by the individual concerned. Prayers, spells, songs, and other are usually used in the recovery process. Emotional factors accompanying religious beliefs need to be considered in the occurrence of possession disorders.
\end{abstract}

Keywords: possession disorder; DID; religious beliefs; case studies; emotions

\begin{abstract}
Abstrak
Keyakinan agama dengan gangguan kesurupan belum banyak disinggung dalam literatur ilmiah. Penelitian ini bertujuan mengeksplorasi keyakinan agama dengan gangguan kesurupan dan bagaimana pemulihannya. Literatur antropologi lebih banyak meneliti kesurupan dari segi budaya. Sebaliknya dalam bidang klinis, sulit menemukan literatur yang membahas kedua variabel tersebut. Metode yang digunakan adalah studi kasus dengan wawancara semi terstruktur untuk pengambilan data. Kriteria partisipan adalah pernah mengalami gangguan kesurupan sesuai dengan PPDGJ III minimal dua kali. Ada enam partisipan yang memenuhi kriteria, semua berjenis kelamin perempuan. Penelitian
\end{abstract}


mengindikasikan kaitan keyakinan agama dengan gangguan kesurupan, baik berkaitan dengan kemunculannya sampai pada upaya pemulihannya. Gangguan kesurupan terjadi ketika keyakinan akan adanya roh halus yang disertai dengan rasa takut tersebut tidak bisa dikontrol oleh individu yang bersangkutan. Doa, mantera, nyanyian dan sarana pemulihan lain biasanya digunakan dalam proses pemulihan. Faktor emosi yang menyertai keyakinan agama perlu diperhatikan pada terjadinya gangguan kesurupan.

Kata kunci: gangguan kesurupan; DID; keyakinan agama; studi kasus; emosi

\section{Pendahuluan}

Kesurupan merupakan fenomena yang universal, ada pada hampir di semua budaya di dunia dan dikenal dengan berbagai nama (Keener, 2010; McCormick \& Goff, 1992). Kesurupan sering kali dikaitkan dengan faktor budaya, khususnya dalam hal keyakinan agama, namun penelitian yang membahas mengenai hubungan keduanya secara khusus sulit ditemukan, utamanya dalam bidang psikologi klinis. Penelitian mengenai kesurupan dari berbagai disiplin ilmu seperti antropologi, sosiologi, sejarah, kedokteran, psikologi, dan penelitian agama menghasilkan kesimpulan yang beragam dan meluas, sehingga menjadi sulit memahami fenomena kesurupan sebagai fenomena tunggal. Secara umum, sudut pandang dalam melihat kesurupan dapat dibedakan menjadi dua, yaitu pandangan medis yang melihat ke dalam etiologi individual dari kesurupan yang dianalisis dalam terminologi kategori psikiatrik. Kedua adalah perspektif antropologi yang melihat ke dalam etiologi sosiokultural, dimana kesurupan dilihat sebagai kerasukan roh dan hubungannya dengan masyarakat (Halloy \& Naumescu, 2012).

Antropologi nampaknya menghindari menggunakan istilah kesurupan sebagai gangguan karena dalam berbagai budaya fenomena kesurupan dekat dengan ritual agama. Cohen (2008) membedakan kesurupan menjadi dua yaitu executive possession dan pathogenic possession. Pada executive possession, entitas roh mengambil alih kendali eksekutif tuan rumah, sehingga mengontrol tingkah laku ketubuhan. Pathogenic possession lebih berkaitan dengan kemunculan kontaminasi (bisa positif maupun negatif) atau kehadiran entitas roh 
yang secara tipikal (tetapi tidak selalu) dimanifestasikan dalam bentuk kesakitan. Beaumont (2014) mengacu pendapat Lewis (1971) membedakan kesurupan menjadi kesurupan pusat dan kesurupan tepi, yang konteksnya lebih pada fungsi dari keyakinan agama. Kesurupan pusat merupakan kesurupan dimana individu yang mengalami kesurupan umumnya dihormati oleh anggota komunitas, karena roh yang merasuk dianggap sebagai roh yang baik dan ritual kesurupan mendukung nilai-nilai masyarakat. Pada kesurupan tepi, entitas yang merasuk justru mengganggu dan berlawanan dengan nilai-nilai komunitas dan individu yang mengalaminya biasanya merupakan anggota masyarakat yang terpinggirkan dan tertekan. Agama Kristen menolak menggambarkan nubuat, pengalaman mistis dan pengalaman roh kudus lainnya sebagai kesurupan pusat. Istilah yang digunakan adalah Kepenuhan Roh (Keener, 2010). Nampaknya berangkat dari konteks inilah, Barat yang dulunya Kristen menggambarkan gangguan kesurupan (kesurupan tepi) sebagai akibat dosa pada awalnya, kemudian ketika medis menjadi arus utama, gangguan kesurupan menjadi patologis (Siswanto, 2007).

Penelitian-penelitian selanjutnya membuka jalan bagi pendekatan antropologi dan klinis untuk mendapatkan pemahaman yang sama mengenai kesurupan, yaitu melihat kesurupan sebagai fenomena disosiasi (Bourguignon, 1989; Somer, 2006). Kalangan klinis membedakan antara kesurupan yang dianggap sebagai gangguan dengan kesurupan yang tidak bisa dinyatakan sebagai gangguan dengan syarat tidak berkaitan dengan budaya ataupun ritual agama yang lazim berlaku (American Psychiatric Association, 2000, 2013). Pada DSM 5, gangguan kesurupan dikelompokkan ke dalam Dissociative Indentity Disorder (DID), menyatu dengan gangguan kepribadian majemuk dulunya. Ini didukung dengan berbagai penelitian terkini yang menunjukkan bahwa antara kepribadian majemuk dan kesurupan merupakan fenomena yang sama dengan penyebutan berbeda karena sudut pandang budaya yang berbeda (Dorahy et al., 2014).

Literatur menjelaskan gangguan kesurupan lebih banyak dialami oleh kaum perempuan dengan latar belakang sosial ekonomi pada lapisan bawah dan pendidikan yang rendah (Bourguignon, 1989; Ram, 2012; Sanaz Ghasemi, Mohsen Kianpoor, Fatemeh Shahabizadeh, 2014; Uszkalo, 2012). Pada kelompok 
ini, kesulitan kehidupan menimbulkan stres yang tinggi sehingga kesurupan bisa menjadi cara menyelesaikan masalah yang diijinkan oleh budaya setempat. Kesurupan memungkinkan individu yang mengalaminya mendapatkan pemenuhan keinginan yang tidak mungkin diungkapkan dalam situasi biasa. Proyeksi rasa bersalah pada suatu roh dapat menjadi cara untuk menyelesaikan tanggung jawab individual dan menjadi suatu bentuk dari fungsi katarsis (Keener, 2010; Razali S.M., 1999). Gangguan kesurupan yang terjadi di Indonesia sebagian besar juga dialami oleh perempuan. Namun berdasarkan temuan penelitian maupun pengalaman praktik peneliti menunjukkan bahwa gangguan kesurupan tersebut bisa dialami oleh perempuan di semua tingkatan sosial ekonomi sehingga status sosial ekonomi dan pendidikan tidak bisa menjadi pembeda yang nyata. Temuan penelitian juga menunjukkan mereka yang mengalami kesurupan biasanya memiliki keyakinan agama yang kuat (Siswanto, 2015). Faktor kepribadian juga ikut memberikan andil terjadinya gangguan kesurupan. Penelitian mengenai gangguan kesurupan di Asia menunjukkan individu yang mengalami kesurupan memiliki ciri kepribadian yang mudah gelisah, ketidakstabilan emosi, mengalami distorsi terhadap realita, mudah tersugesti dan suka melebih-lebihkan (Gaw, A. C., Ding, Q.-z. M., Levine, R. E., \& Gaw, 1998; Siswanto, 2015; Yeong Ng, B., Keong Yap, A., Su, A., Lim, D., \& How Ong, 2002).

Interaksi antara faktor kepribadian dan keyakinan agama memberikan resiko terjadinya gangguan kesurupan. Mereka yang mengalami gangguan kesurupan biasanya didahului dengan perasaan takut karena berada dalam situasi atau tempat yang diyakini ada roh halusnya. Keyakinan mengenai adanya roh halus menjadi semacam sugesti verbal, yang dalam prinsip hipnosis, gagasan adanya roh halus tersebut secara reflek memicu respon ideo-motor, ideo sensitif dan ideo sensori. Gagasan secara otomatis mengaktifkan reaksi fisiologis pada individu yang memang memiliki disposisi kepribadian yang membuatnya mudah tersugesti dan kurang mampu mengontrol emosi (Vandenberg, 2012).

Ajaran agama yang meyakini keberadaan Tuhan, setan, jin dan roh halus nampaknya pada individu tertentu dihayati secara personal menjadi semacam 
delusi atau over value idea (OVI) yang merupakan suatu kontinum (Radden, 2014). Delusi diartikan sebagai suatu keyakinan yang keliru yang didasarkan pada kesimpulan yang keliru mengenai kenyataan di luar meskipun mendapatkan bukti atau petunjuk yang tidak dapat dibantah dan jelas yang berlawanan dengan objek delusinya (American Psychiatric Association, 2000). Sedangkan OVI dicirikan dengan secara kuat memegang keyakinan yang keliru yang biasanya tidak dianggap sebagai delusional/waham tetapi sebagai gagasan yang diberi penilaian berlebihan (Mullen \& Gillett, 2014). Pada individu semacam ini, keyakinan agama justru menjadi sumber isi delusi atau OVI mereka sehingga meningkatkan resiko terjadinya gangguan mental, utamanya gangguan kesurupan.

Penelitian ini ingin mengungkap bagaimana keyakinan agama dan gangguan kesurupan yang dialami oleh individu? Bagaimana keyakinan agama digunakan untuk mengatasi gangguan kesurupan yang dialami? Sepanjang studi literatur, belum ada yang membahas khusus peranan keyakinan agama terhadap gangguan kesurupan. Literatur membahas gangguan kesurupan dengan pengalaman abuse masa kanak-kanak (International Society for the Study of Dissociation, 2004; International Society for the Study of Trauma and Dissociation 2011), jenis kelamin yang umumnya dialami oleh perempuan, dengan status sosial ekonomi di bawah dan tingkat pendidikan yang rendah (Bourguignon, 1989; Ram, 2012; Sanaz Ghasemi, Mohsen Kianpoor, Fatemeh Shahabizadeh, 2014; Uszkalo, 2012), kepribadian (Gaw, A. C., Ding, Q.-z. M., Levine, R. E., \& Gaw, 1998; Siswanto, 2015; Yeong Ng, B., Keong Yap, A., Su, A., Lim, D., \& How Ong, 2002), dan pengasuhan (Holland, 2000).

\section{Metode}

Penelitian ini menggunakan metode studi kasus. Studi kasus merupakan strategi yang lebih cocok bila pokok pertanyaan suatu penelitian berkenaan dengan bagaimana dan mengapa, bila peneliti hanya memiliki sedikit peluang untuk mengontrol peristiwa-peristiwa yang akan diselidiki. Studi kasus menyediakan alat bagi peneliti untuk mempelajari fenomena yang kompleks dalam konteksnya. Kalau pendekatannya diterapkan secara benar, ini menjadi 
metode yang berguna untuk mengembangkan teori, mengevaluasi program dan mengembangkan intervensi (Baxter \& Jack, 2008; Yin, 2015). Analisis kasus pertama menjadi dasar peneliti untuk memformulasi hipotesis tentatif yang kemudian dapat dieksplorasi dalam terang kasus-kasus berikutnya. Dengan setiap kasus baru, teori yang muncul dimodifikasi dalam rangka supaya dapat menghitung semua hal yang berkaitan dengan fenomena yang sedang diteliti (Willig, 2008).

Para partisipan diberikan penjelasan mengenai tujuan penelitian serta gambaran mengenai proses pengambilan data. Setelah mereka menyetujui kemudian diberikan informed consent yang pada intinya berisi penjelasan manfaat penelitian, penjelasan kemungkinan risiko dan ketidaknyamanan yang dapat ditimbulkan, persetujuan subyek dapat mengundurkan diri kapan saja, dan jaminan anonimitas dan kerahasiaan. Penelitian ini pada dasarnya tidak memiliki risiko yang serius pada partisipan karena menitikberatkan pada keyakinan agama yang dimiliki oleh partisipan beserta bagaimana proses mendapatkannya serta pengalaman sekitar kesurupan yang dialami. Namun untuk mengantisipasi risiko negatif yang muncul misalnya suasana perasaan partisipan menjadi berubah setelah wawancara dilakukan, peneliti akan selalu melakukan pengecekan, untuk memastikan bahwa kondisi partisipan betul-betul wajar setelah sesi wawancara berakhir. Para partisipan juga dibantu untuk mampu mengantisipasi munculnya kesurupan yang mungkin akan dialami kembali pada waktu yang akan datang dengan teknik yang dikembangkan oleh peneliti. Teknik tersebut meliputi penyadaran nafas, melakukan penilaian terhadap perasaan yang dialami serta gerakan menyilang sederhana untuk menetralkan perasaan.

Pengambilan data menggunakan wawancara semi terstruktur. Pada wawancara semi terstruktur peneliti memiliki ide dari wilayah minat dan beberapa pertanyaan yang akan ditujukan. Pada saat yang sama ada harapan untuk mencoba memasuki sejauh mungkin dunia psikologis dan sosial dari partisipan. Dalam relasi ini, partisipan dapat dianggap sebagai ahli atas pokok penelitian dan oleh karena itu harus diijinkan mendapatkan kesempatan yang semaksimal mungkin untuk mengatakan kisahnya sendiri (Smith, 1995). Wawancara dengan partisipan 
selesai ketika tidak ada lagi tema atau data baru yang muncul, dilanjutkan dengan partisipan berikutnya. Proses pencarian partisipan dilakukan terus menerus sampai mencapai saturasi, sehingga tidak ada lagi data baru yang relevan, serta hubungan antar katagori sudah mapan dan tervalidasi. Ini yang dinamai sebagai saturasi teoritis (Strauss \& Corbin, 1998).

Kredibilitas penelitian dilakukan dengan cara semua pertemuan wawancara semi terstruktur direkam. Partisipan mengalami wawancara lebih dari satu kali, sampai data yang dibutuhkan oleh peneliti dianggap sudah mengalami saturasi. Rekaman hasil wawancara kemudian ditranskrip. Partisipan kemudian diminta untuk membaca kembali hasil transkrip untuk melakukan koreksi maupun tambahan data yang mungkin belum ada pada waktu wawancara dilakukan. Data yang digunakan dalam proses penelitian adalah data hasil transkrip yang telah dikonfirmasi oleh partisipan (Poerwandari, 1997). Setelah proses analisis dilakukan, hasilnya kemudian dikirimkan lagi kepada para partisipan untuk mendapatkan koreksi dan persetujuan kembali, baik berkaitan dengan narasi yang dibuat oleh peneliti maupun pemahaman yang muncul dari narasi tersebut. Proses ini disebut juga sebagai validitas komunikatif (Poerwandari, 1997) atau validitas partisipan, yaitu umpan balik terhadap temuan-temuan dalam penelitian dari para partisipan. Partisipan memberikan komentar, elaborasi, tantangan atau memvalidasi analisis mengenai dirinya (Willig, 2008). Kredibilitas penelitian ini juga disebut sebagai member cheking, interpretasi peneliti terhadap data dibagikan dengan partisipan dan partisipan mendapatkan kesempatan untuk mendiskusikan dan menjelaskan interpretasi dan menyumbangkan pandangan yang baru atau tambahan terhadap isu yang diteliti (Baxter \& Jack, 2008).

Partisipan penelitian adalah mereka yang bersedia terlibat dalam penelitian yang memenuhi syarat penelitian, yaitu pernah mengalami gangguan kesurupan seperti dalam kriteria PPDGJ III/ICD 10/DSM-IV-TR/DSM 5 (American Psychiatric Association, 2000, 2013; Departemen Kesehatan RI Direktorat Jenderal Pelayanan Medik, 1993; Maslim, 1998; Somer, 2006; World Health Organization, 1992). Kriteria tambahan yang ditetapkan oleh peneliti adalah para partisipan pernah mengalami gangguan kesurupan minimal dua kali. Pada 
penelitian didapatkan enam partisipan yang memenuhi kriteria, semua berjenis kelamin perempuan. Deskripsi para partisipan dapat dilihat pada Tabel 1.

Tabel 1. Deskripsi Para Partisipan

\begin{tabular}{|c|c|c|c|c|c|c|}
\hline Partisipan & Agama & $\begin{array}{c}\text { Usia saat } \\
\text { wawancara }\end{array}$ & Pendidikan & $\begin{array}{c}\text { Jenis } \\
\text { kelamin }\end{array}$ & Etnis & Domisili \\
\hline A & Islam & 20 th & Mhsw S1 & Perempuan & Bugis & $\begin{array}{l}\text { Makassar (Sulawesi } \\
\text { Selatan) }\end{array}$ \\
\hline B & Islam & 21 th & Mhsw S1 & Perempuan & Kaili & $\begin{array}{l}\text { Poso (Sulawesi Tengah) } \\
\text { Bulukumba (Sulawesi }\end{array}$ \\
\hline $\mathrm{C}$ & Islam & 20 th & Mhsw S1 & Perempuan & Konjo & Selatan) \\
\hline $\mathrm{D}$ & Kristen & 22 th & SMA & Perempuan & Jawa & Jawa tengah \\
\hline $\mathrm{E}$ & $\begin{array}{l}\text { Hindu } \\
\text { Bali }\end{array}$ & 27 th & Mhsw S2 & Perempuan & Bali & Palu (Sulawesi Tengah) \\
\hline $\mathrm{F}$ & Islam & 22 th & Mhsw S1 & Perempuan & Jawa & Jawa Tengah \\
\hline
\end{tabular}

Awal serangan gangguan kesurupan dan frekuensi terjadinya gangguan kesurupan bisa dilihat pada Tabel 2.

Tabel 2 Deskripsi Gangguan Kesurupan Para Partisipan

\begin{tabular}{cll}
\hline Partisipan & \multicolumn{1}{c}{$\begin{array}{c}\text { Pertama kali } \\
\text { kesurupan }\end{array}$} & \multicolumn{1}{c}{ Frekuensi Gg. Kesurupan } \\
\hline A & $\begin{array}{l}\text { SD kelas 6 (12 th) } \\
\text { SMA kelas III (18 th) }\end{array}$ & $\begin{array}{l}\text { Dua kali mengalami kesurupan, yang kedua SMP kelas III. } \\
\text { Tiga kali mengalami kesurupan, kedua awal kuliah yang terjadi } \\
\text { berulang kali sampai dipulangkan dulu ke rumah selama sebulan, dan } \\
\text { ketiga sewaktu KKN. } \\
\text { Berkali-kali, setiap episode kesurupan terjadi beberapa kali, kedua dan } \\
\text { seterusnya terjadi di SMA kelas I \& III, semester awal kuliah. } \\
\text { Sehari bisa berkali-kali; seminggu berulang kali; setelah dilayani oleh } \\
\text { pendeta hanya ketika sakit hati, jengkel, atau mendengarkan suara } \\
\text { reog. }\end{array}$ \\
C & SMP kelas II (12 th) \\
D & SMP kelas I (13 th) & $\begin{array}{l}\text { Hampir tiap semester ketika kuliah di Jawa; ada yang berulang kali } \\
\text { dalam waktu berdekatan. } \\
\text { Awalnya ketempelan; kesurupan ketika kuliah saat Makrab, setelah itu } \\
\text { setiap merasa bermasalah muncul gg kesurupan }\end{array}$ \\
E & SMA kelas II (17 the \\
F & SMA kelas I sewaktu \\
di pesantren (16 th)
\end{tabular}

\section{Hasil}

Berdasarkan analisis verbatim terhadap semua partisipan, didapatkan tema-tema umum yang berkaitan dengan keyakinan agama dan kaitannya dengan gangguan kesurupan yang mereka alami.

\section{Emosi negatif diikuti perubahan ketubuhan}

Sebelum serangan kesurupan terjadi, para partisipan mengalami emosi yang negatif. Perasaan negatif yang muncul umumnya adalah perasaan takut atau 
cemas. Pada partisipan A, D, dan E, selain perasaan takut, kesurupan bisa dipicu oleh perasaan sedih karena masih berduka ditinggal ayah (A); jengkel dan sakit hati karena ayah (D), dan kemarahan (E). Emosi yang negatif tersebut akhirnya mempengaruhi fungsi ketubuhan dan ketika tidak bisa lagi mengontrol emosi yang muncul, gangguan kesurupan terjadi. Perubahan ketubuhan yang dirasakan bisa berbeda antar partisipan.

Partisipan A mengalami gangguan kesurupan setelah pulang dari rumah lamanya. Setelah membersihkan rumah, biasanya dia bermain dengan teman-teman lamanya, namun hari itu teman-temannya tidak ada yang datang. Rumah lama membawa kenangan pada ayah yang sudah meninggal. Selama ini A, dekat dengan ayahnya. Selama di perjalanan pulang kembali ke tempat tinggal yang baru A lebih banyak diam. Sesampai di rumah A tiba-tiba demam tinggi dan tidak sadarkan diri. A dibawa ke rumah sakit, namun dokter tidak menemukan penyebab sakitnya. A mengalami kesurupan di rumah sakit. Setiap hari A minta kaus kaki dengan menggunakan bahasa Belanda. Partisipan B ketika akan mengalami gangguan kesurupan, muncul perasaan ketakutan, yang membuatnya merasa tangannya dingin. Gejala lain yang menyertai adalah muncul perasaan tidak enak dan ingin menangis, jantung berdebar-debar dan badan merasa dingin. Partisipan $C$ merasa seperti lemas, seperti melihat bayangan hitam, merasa seperti diburu, seperti mau dibunuh, dada sesak sehingga susah mengatur nafas, tersengalsengal. Partisipan D ketika mengalami ketakutan karena berpikir mengenai roh halus atau sakit hati karena bapak/teman, merasakan kaki kanannya menjadi kaku/mati dan menjalar ke keseluruh tubuh. Partisipan E sebelum mengalami gangguan kesurupan, muncul perasaan tidak enak, ingin marah, ingin teriak, badan mulai merasa panas. Partisipan F sebelum mengalami gangguan kesurupan, muncul perasaan takut, berat sekali, pusing di kepala bagian belakang.

\section{Tempat dikaitkan dengan roh halus yang memunculkan ketakutan}

Para partisipan mengalami gangguan kesurupan yang berkaitan dengan tempat tertentu, dimana tempat tersebut dianggap ada penunggu/roh halusnya. Atau di tempat tersebut pernah terjadi peristiwa ada orang yang meninggal sehingga menjadi angker. Keyakinan ini kemudian menimbulkan perasaan takut yang kuat.

Partisipan A pertama kali mengalami gangguan kesurupan setelah bermain di bawah pohon besar. Demikian juga dengan partisipan $C$, yang sebelum mengalami gangguan kesurupan melihat di bawah pohon besar seperti ada hantu yang besar. Partisipan D dulu pada waktu masih 
kesurupan sering merasa takut, seperti kalau lewat kuburan misalnya, pikiran langsung yang bukan-bukan seperti kalau ditemui roh halus. Ketika melewati pohon besar atau membaui bunga/kemenyan bulu kuduk langsung berdiri. Partisipan E meyakini ada yang menjadi penunggu di kamar penginapan yang ditempatinya, sehingga dia meminta ijin pada roh penunggu tersebut. Partisipan E juga mengkaitkan gangguan kesurupan yang dialami di kontrakannya karena dulu ada yang bunuh diri di sana. Partisipan F meyakini bahwa kamar pondokannya ada penunggunya sehingga seringkali yang menghuni kamar tersebut mengalami gangguan kesurupan. Partisipan juga hampir mengalami gangguan kesurupan ketika melewati Alas Roban yang memang dikenal sebagai tempat yang angker. "Terus itu saya lihat ada tangan ada kepala ... benar-benar .. terus di belakang itu rasanya berat... ngikutin ... saya cepet-cepet pulang."

\section{Situasi atau kejadian tertentu yang diasosiasikan dengan pengalaman emosional}

Peristiwa gangguan kesurupan pada para partisipan berkaitan dengan situasi atau kejadian yang umumnya diasosiasikan dengan pengalaman emosional yang pernah dialami di masa lalu. Asosiasi ini bersifat subsadar, tidak disadari oleh partisipan namun melalui refleksi bisa melihat kaitannya dengan kejadian yang pernah dialami. Situasi kecapaian karena mengikuti kegiatan yang di luar biasanya juga memicu munculnya gangguan kesurupan. Teman yang terlebih dahulu mengalami kesurupan, juga memicu terjadinya gangguan kesurupan pada partisipan.

Partisipan A pernah mengalami gangguan kesurupan saat keluarga besarnya sedang membangun kuburan neneknya. Ingatan akan nenek nampaknya menghubungkannya kembali dengan pengalaman kedukaan ditinggalkan oleh orang - orang dekat, terutama ayah. Peristiwa membersihkan rumah lama, yang memiliki kenangan pada orang-orang yang telah tiada itu menguatkan perasaan kedukaannya sehingga akhirnya mengalami gangguan kesurupan. Pada partisipan B, gangguan kesurupan terjadi pada waktu mengikuti acara camp di fakultasnya. B mengalami kelelahan karena banyak energi yang digunakan untuk kegiatan naik gunung, adventure, dan kehujanan. Kejadian kesurupan terjadi bertepatan dengan waktu mahgrib yang diyakini adalah waktu keluarnya roh halus/jin. Bunyi telepon di tengah malam pada partisipan C memicu munculnya perasaan takut pada kematian. Bunyi telepon itu mengingatkannya pada peristiwa nenek yang meninggal dan bagaimana dia menggantikan ibunya memandikan nenek dengan rasa takut karena waktu itu dia masih SMP. Bunyi telepon tersebut selain berkaitan dengan 
kematian nenek juga berkaitan dengan kematian saudara di keluarga besar yang beruntun dalam waktu berdekatan karena pemberitahuan mengenai kabar meninggalnya saudara melalui telepon. Partisipan D mengalami gangguan kesurupan setiap mendengarkan suara gamelan. Bunyi gamelan membuatnya gelisah, kemudian merasa badannya menjadi panas, lalu kejang dan akhirnya mengalami gangguan kesurupan. Oleh karena itu setiap kali ada pertunjukkan reog di kampungnya, dia diungsikan ke tempat lain untuk menghindari kesurupan. Reog dan bunyi gamelan mengingatkannya pada masa kecil bersama kakek yang menjadi dukun reog. Partisipan E mengalami gangguan kesurupan ketika banyak tugas di perkuliahan dan menjelang ujian semester. Partisipan F mengalami gangguan kesurupan setelah melihat temannya mengalami kesurupan. Partisipan menjadi semakin takut setelah teman pesantren partisipan dulunya membenarkan cerita partisipan. Apalagi partisipan diberikan mantera doa untuk melindungi diri, itu justru membuat partisipan menjadi semakin takut.

\section{Cemas dan gelisah berkaitan dengan keyakinan agama dan ritual yang diajarkan}

Partisipan merasa gelisah dan cemas ketika tidak melakukan apa yang semenjak kecil diajarkan dalam keluarga berkaitan dengan keyakinan agama yang dianut.

Partisipan B dan C semenjak kecil diajar harus pulang sebelum maghrib tiba. Pada waktu maghrib banyak setan yang keluar. Ini membuat partisipan $B$ mengalami rasa takut ketika sedang berada di jalan pada waktu maghrib. Partisipan C sampai tidak pernah mengikuti kegiatan organisasi di kampusnya pada waktu malam karena takut. Ketika terlambat untuk sholat, muncul perasaan seperti akan meninggal, sehingga menimbulkan kecemasan. Partisipan D merasa takut kalau tidak ke gereja, itu artinya jauh dari Tuhan sehingga akan ditempeli roh halus kembali. Partisipan E mengkaitkan kejadian yang dialaminya dengan karma yang pernah dilakukannya. Partisipan F menjadi semakin takut setiap mendengarkan cerita berkaitan dengan dunia ghaib dari teman-teman pesantrennya. Cerita ini sebelumnya didapatkannya dari bapaknya ketika masih kecil saat menonton TV yang menayangkan dunia ghaib, juga cerita dari bapak sendiri.

\section{Kecenderungan pola obsesif kompulsif}

Selain rasa takut, para partisipan memiliki kecenderungan pola obsesif kompulsif, yaitu harus melakukan seperti apa yang sudah dipikirkan. Kalau tidak melakukan seperti apa yang sudah dipikirkan/direncanakan sebelumnya, mereka 
merasa gelisah dan bahkan mengalami kecemasan dan ketakutan. Pola kecenderungan obsesif kompulsif ini khususnya berkaitan dengan ritual ibadah seperti melakukan sholat/sembahyang/ke gereja.

Partisipan A sudah ditanamkan untuk rajin sholat tepat waktu, karena diajarkan kalau tidak sholat yang mendoakan bapaknya tidak ada sehingga bapak kepanasan di dalam kubur. Partisipan A menjadi panik dan cemas serta merasa tidak lega kalau terlambat atau tidak melakukan sholat. Partisipan B merasa cemas karena akan mengalami sesuatu yang buruk bila terlambat sholat atau marah terhadap seseorang dan mengeluarkan kata-kata kasar. Partisipan C bila tidak melakukan sholat seperti apa yang sudah direncanakan, muncul perasaan tidak tenang, perasaan dingin menjalar dari kaki, perasaan tidak enak dan tidak karuan. Setelah melakukan sholat, semua perasan tersebut menurun dan kemudian menghilang. Partisipan juga merasa harus mencari di internet tanda-tanda orang yang mau mati dan mencocokkannya dengan perasaan mau meninggal yang dialaminya. Partisipan D merasa harus ke gereja dan rutin membaca kitab suci yang berkaitan dengan roh halus karena takut mengalami kesurupan kembali bila tidak ke gereja. Partisipan E merasa harus melakukan apa yang sudah diniatkan untuk sembahyang, persis seperti apa yang sudah diniatkan tersebut. "Saya udah terlanjur berniat harus ke pura sekarang, kalau tidak ke pura itu tidak enak, meski ada resiko ketinggalan pesawat. Kalau tidak melakukan apa yang sudah diniatkan secara persis, muncul perasaan tidak nyaman, tidak tenang, gelisah, tidak bisa tidur, meski sudah diganti dengan sembahyang di rumah."

Partisipan tidak lagi mengalami gangguan kesurupan ketika pola kecenderungan obsesif kompulsif ini berhasil diubah. "Kalau ada apa-apa tidak usah dipikir secara mendalam, tidak perlu dipedulikan, akhirnya sekarang menjadi biasa." (Partisipan D).

\section{Kesurupan terus berulang karena terjadi "lingkaran setan"}

Partisipan rata-rata mengalami beberapa kali serangan gangguan kesurupan pada satu episode gangguan kesurupan. Ini nampaknya terjadi karena kecemasan dan ketakutan yang tidak bisa dikendalikan membuat partisipan mengalami kelelahan dan akhirnya tidak bisa beristirahat dengan baik. Pada akhirnya gangguan kesurupan dialami kembali karena emosi negatif pada akhirnya menguasai partisipan.

Partisipan B mengalami ketakutan untuk tidur setelah sadar dari gangguan kesurupan. Partisipan berusaha membuka mata terus karena 
muncul perasaan tidak enak saat menutup mata. Ini membuatnya tidak bisa tidur. Pada akhirnya partisipan justru mengalami gangguan kesurupan kembali karena tidak bisa lagi menguasai perasaan takutnya. Partisipan $C$ dipenuhi perasaan tidak karuan karena takut merasa badannya panas dan seperti mau meninggal. Ini membuat kepalanya berdenyut-denyut dan jantungnya berdebar keras. Reaksi fisiologis yang dirasakan ini membuatnya semakin tidak karuan dan pikiran akan meninggal semakin kuat. Partisipan D terbangun di tengah malam karena tidak tenang ketika tidak melakukan doa puasa di gereja. Pada akhirnya dia mengalami kesurupan ketika tidak bisa menguasai perasaannya. Partisipan E menjadi tidak enak kalau merasa melanggar janji dengan Tuhan, baginya Tuhan selalu tepat waktu sehingga dia pun tidak boleh melanggar janji. Partisipan F biasanya tidak bisa tidur sampai beberapa hari setelah melihat makhluk halus pada waktu kesurupan. Ini membuatnya mengalami kesurupan kembali.

\section{Pemulihan gangguan kesurupan}

Umumnya keluarga menggunakan orang pintar/rohaniwan untuk mengatasi gangguan kesurupan yang dialami oleh partisipan. Dukun, Ustadz, Pendeta adalah orang-orang yang biasanya diminta untuk membantu pemulihan. Mereka dianggap memiliki kemampuan untuk mengusir roh halus/jin yang masuk ke dalam tubuh korban.

Pemulih baik dukun/rohaniwan biasanya menggunakan beberapa cara untuk membantu pemulihan. Dukun biasanya menggunakan sarana benda-benda tertentu. Sedangkan rohaniwan, selain menggunakan doa, nyanyian, mantra, atau membaca kitab suci dalam proses pemulihan korban, ada juga yang menggunakan sarana benda tertentu. Cara-cara yang digunakan kadang berhasil, kadang tidak berhasil. Cara-cara yang tidak jelas proses keberhasilannya adalah dengan membaca doa, mantra dan kitab suci. Cara yang biasanya relatif berhasil adalah dengan bernyanyi.

Partisipan A memanggil ustad pada waktu mengalami kesurupan yang pertama. Ustad menggunakan doa dan air yang diusapkan ke kepala. Setelah itu keringatnya langsung keluar, dan ketika sadar diberi minum air. Pada kesurupan yang kedua, dipanggilkan orang pintar yang sudah yang nenek-nenek. Nenek tersebut menggunakan bulu ayam yang kemudian dijepitkan di antara dua jari kaki. Partisipan kemudian menjadi sadar karena merasakan sakit yang sangat seperti kedua jari kakinya patah. Setelah itu diberi minum. Partisipan B dipanggilkan bermacam-macam penyembuh, baik dukun maupun ustad. Ustad 
melakukan pemulihan dengan memegangnya dan menyuruhnya meminum air yang sudah didoakan. Partisipan $C$ dibacakan ayat-ayat Alquran oleh ustad. Pada waktu dibacakan justru badannya menjadi seperti panas, kemudian berteriak-teriak dan akhirnya kehilangan kesadaran. Pada serangan gangguan kesurupan yang lain, partisipan $C$ ditangani oleh orang pintar. Partisipan $C$ dimandikan oleh orang pintar tersebut. Namun setelah itu muncul perasaan ingin kembali kepada orang pintar tersebut, terutama pada saat maghrib. Partisipan D merasa doa tidak membantu. Ketika didoakan, setannya seperti pura-pura pergi, setelah didoakan lalu kembali lagi. Justru dengan menyanyi lagu gereja dan menghayati lagu yang dinyanyikan, gejala ketubuhan yang dialami seperti kaki yang kaku lama-lama menghilang dan partisipan tidak mengalami kesurupan. Untuk mencegah berulangnya kesurupan, partisipan menjadi rajin ke gereja dan membaca kitab suci yang berhubungan dengan roh. Partisipan lama-lama merasa hatinya tentram dan seperti memahami. Namun kegiatan ini harus terus dilakukan dan partisipan menganggapnya seperti dituntun. Partisipan E sempat ditangani oleh ustad dan pendeta Kristen dengan cara dibacakan ayat dari kitab suci, namun tidak berhasil. Mereka malah ditantang oleh roh yang merasuki. Pendeta Hindu mencoba untuk menggunting kuku partisipan, malah ditendang oleh partisipan. Partisipan menjadi tenang justru ketika sepupunya menempelkan kitab Weda ke muka partisipan. Partisipan F dibantu oleh ustad ketika mengalami gangguan kesurupan. Ustad menggunakan ritual seperti dikramasi oleh keluarga kandung menggunakan air wudlu dari tujuh mushola yang berbeda, setelah itu dimandikan oleh ustad. Partisipan jarang melakukan sholat, karena meskipun tahu sholat bisa membentengi diri, namun dengan melakukan sholat, partisipan justru semakin bisa melihat makhluk halus dengan jelas.

\section{Pembahasan}

Faktor emosi nampaknya penting untuk diperhitungkan sebagai faktor utama terjadinya gangguan kesurupan. Para partisipan mengalami gangguan kesurupan ketika tidak bisa lagi mengendalikan emosinya, terutama emosi ketakutan. Ketakutan atau emosi negatif lainnya seperti kedukaan muncul berkaitan dengan tempat/situasi yang dianggap angker atau mengingatkan kembali partisipan pada pengalaman kedukaan yang pernah dialami. Faktor kecapaian karena banyak kegiatan atau kurang istirahat membuat partisipan kurang mampu mengendalikan emosinya. Akhirnya emosi tersebut menguasai mereka, yang berlanjut pada terjadinya perubahan ketubuhan, dan terjadilah gangguan kesurupan. Individu yang mengalami ketakutan atau kecemasan yang tidak 
terselesaikan pada akhirnya akan mengembangkan gejala-gejala disosiasi (Howell, 2005). Faktor emosi dan pengaruhnya pada kesehatan mental telah dirumuskan dengan jelas di DSM 5 (American Psychiatric Association, 2013).

Amigdala dan stimulus yang dikondisikan menjadi pencetus respon emosi jangka panjang yang sangat kuat. Emosi lebih lanjut dikeluarkan dan diintensifkan menjadi secara terkondisi diasosiasikan dengan Tuhan, hantu dan setan, yang menjadi isi dari sistem keyakinan agama (Alcorta \& Sosis, 2005). Keyakinan agama para partisipan, khususnya yang berkaitan dengan dunia roh yang disertai dengan perasaan takut nampaknya menjadi pemicu munculnya rasa takut tersebut. Partisipan juga mengalami perasaan tidak nyaman ketika tidak melakukan ritual agama seperti bersembahyang pada waktunya. Berada di tempat yang asing karena mengikuti kegiatan khusus dengan acara yang membuat waktu untuk bersembahyang menjadi terlambat, bisa menjadi pemicu terjadinya perasaan tidak enak tersebut. Pola kepribadian yang cenderung obsesif kompulsif membuat perasaan tidak enak tersebut berlangsung lama dan bahkan pada akhirnya tidak bisa dikuasai. Keyakinan agama menjadi semacam otosugesti yang ada akhirnya menguasai individu (Vandenberg, 2012).

Penanganan gangguan kesurupan yang dialami oleh para partisipan pada umumnya melibatkan rohaniwan/pemimpin agama. Doa atau membaca mantera menjadi cara paling umum untuk memulihkan partisipan. Sarana lain yang digunakan dalam doa adalah dengan menggunakan air yang didoakan kemudian diminumkan kepada partisipan. Doa atau membaca mantera menjadi cara paling umum karena diyakini mampu mengusir roh jahat yang merasuki partisipan (Walter \& Fridman, 2004). Cara lain adalah dengan menggunakan nyanyian, khususnya pada partisipan yang beragama nasrani. Pada partisipan muslim, ada juga nyanyian seperti sholawat yang digunakan. Namun melakukan pengusiran pada roh halus yang merasuk dengan nyanyian jarang digunakan pada partisipan penelitian ini.

Pada penelitian ini doa/membaca mantera nampaknya memiliki tingkat efektifitas yang kurang jelas untuk pemulihan para partisipan. Doa kadang membantu namun kadang juga tidak efektif digunakan untuk melakukan 
pemulihan. Bahkan doa bisa menjadi pemicu terjadinya gangguan kesurupan kembali karena justru oleh partisipan diasosiasikan dengan keadaan bahaya karena keberadaan entitas roh. Ini selaras dengan temuan-temuan penelitian sebelumnya yang menyatakan bahwa berdoa/mengalihkan perhatian secara positif berkaitan dengan nyeri dan ketidakmampuan, tetapi tidak berkaitan terhadap depresi dan kecemasan. Temuan lain juga menyatakan bahwa ternyata berdoa tidak menjadi suatu prediktor yang penting pada simtomatologi dari orang tua yang berduka (Park \& Cohen, 1992). Nyanyian jarang digunakan dalam proses pemulihan ganguan kesurupan pada partisipan penelitian, padahal justru memberikan hasil yang lebih baik daripada doa. Nyanyian membantu partisipan untuk lebih menghayati emosinya dan menguasai emosinya kembali (Walter \& Fridman, 2004).

\section{Kesimpulan dan Saran}

Gangguan kesurupan di Indonesia nampaknya memiliki kaitan dengan keyakinan agama. Partisipan yang mengalami gangguan kesurupan memiliki keyakinan agama yang disertasi oleh rasa takut. Bila rasa takut tersebut tidak bisa dikendalikan, resiko mengalami gangguan kesurupan menjadi tinggi. Proses pemulihan gangguan kesurupan umumnya menggunakan ritual agama seperti doa/mantera dan nyanyian, dengan efektifitas yang berbeda. Pada para partisipan, doa nampaknya tidak jelas efektifitasnya, padahal menjadi cara yang paling umum digunakan. Bahkan pada kasus, doa memicu kemunculan gangguan kesurupan kembali. Nyanyian jarang digunakan dalam penanganan gangguan kesurupan, namun nampaknya lebih efektif dibandingkan dengan doa. Penelitian lebih lanjut mengenai cara penanganan gangguan kesurupan dengan menggunakan sarana agama menarik untuk dilakukan sehingga bisa memberikan gambaran unsur-unsur mana yang mendukung proses pemulihan dan sebaliknya, unsur-unsur yang justru memicu terjadinya gangguan kesurupan kembali.

\section{DAFTAR PUSTAKA}

Alcorta, C. S., \& Sosis, R. (2005). Sacred Symbols. Human Nature, 16(4), 323- 
359. https://doi.org/10.1007/s12110-005-1014-3

American Psychiatric Association. (2000). Diagnostic and Statistical Manual of Mental Disorders, Fourth Edition, Text Revision (DSM-IV-TR). In Diagnostic and Statistical Manual of Mental Disorders, Fourth Edition, Text Revision (DSM-IV-TR). https://doi.org/10.1176/appi.books.9780890423349

American Psychiatric Association. (2013). Diagnostic and Statistical Manual of Mental Disorders, Fifth Edition. In 978-0-89042-554-1.

Baxter, P., \& Jack, S. (2008). Qualitative Case Study Methodology: Study Design and Implementation for Novice Researchers. The Qualitative Report Volume, 13(4), 544-559. https://doi.org/10.2174/1874434600802010058

Beaumont, C. (2014). A Theological Engagement with Current Theories of Dissociative Identity Disorder Using the Mimetic Theory of René Girard (Durham University). Retrieved from http://etheses.dur.ac.uk/10609/

Bourguignon, E. (1989). Multiple personality, possesion trance, and the psychic unity of mankind. Ethos, 371-384.

Cohen, E. (2008). What is spirit possession? Defining, comparing, and explaining two possession forms. Ethnos, 73(1), 101-126. https://doi.org/10.1080/00141840801927558

Departemen Kesehatan RI Direktorat Jenderal Pelayanan Medik. (1993). PPDGJ III: Pedoman Penggolongan dan Diagnosis Gangguan Jiwa di Indonesia III. Jakarta: Departemen Kesehatan.

Dorahy, M. J., Brand, B. L., Şar, V., Krüger, C., Stavropoulos, P., MartínezTaboas, A., ... Middleton, W. (2014). Dissociative identity disorder: An empirical overview. Australian and New Zealand Journal of Psychiatry, 48(5), 402-417. https://doi.org/10.1177/0004867414527523

Gaw, A. C., Ding, Q.-z. M., Levine, R. E., \& Gaw, H. -f. L. (1998). The Clinical Characteristics of Possession Disorder Among 20 Chinese Patients in the Hebei Province of China. Psychiatr Serv, 49, 360-365.

Halloy, A., \& Naumescu, V. (2012). Journal of Learning Spirit Possession: An Introduction. Ethnos: Journal of Anthropology, 77(2), 155-176. https://doi.org/http://dx.doi.org/10.1080/00141844.2011.618271

Holland, D. (2000, December). Culture and Dissociation in Toraja. transcultural psychiatry, 37 (4), 545-559. 
Howell, E. F. (2005). The Dissociative Mind. https://doi.org/10.1017/CBO9781107415324.004

ISSD, I. S. (2004). Guidelines for the Evaluation and Treatment of Dissociative Symptoms in Children and Adolescents. Journal of Trauma \& Dissociation, 5(3), 119-150. doi:10.1300/J229v05n03_09

ISSTD, I. S. (2011, March 03). Guidelines for Treating Dissociative Identity Disorder in Adults, Third Revision: Summary Version. Journal of Trauma \& Dissociation, 12, 2, 188-212. doi:10.1080/15299732.2011.537248

Keener, C. S. (2010). Spirit Possession as a Cross-Cultural Experience. Bulletin for Biblical Research, 20(2), 215-236.

Maslim, R. (1998). Buku Saku Diagnosis Gangguan Jiwa Rujukan Ringkas dari PPDGJ-III. Jakarta: Bagian Ilmu Kedokteran Jiwa FK Unika Atma Jaya.

McCormick, S., \& Goff, D. C. (1992). Possession states: Approaches to clinical evaluation and classification. Behavioural Neurology, 5(3), 161-167. https://doi.org/10.3233/BEN-1992-5304

Mullen, R., \& Gillett, G. (2014). Delusions: A Different Kind of Belief? Philosophy, Psychiatry, \& Psychology, $21 \quad$ (1), 27-37. https://doi.org/10.23943/princeton/9780691151601.003.0008

Park, C., \& Cohen, L. H. (1992). Religious Beliefs and Practices and the Coping Process. In B. N. Carpenter (Ed.), Personal coping: theory, research, and application (pp.

185-198). https://doi.org/10.1017/CBO9781107415324.004

Poerwandari, E. (1997). Pendekatan Kualitatif dalam Penelitian Psikologi. Jakarta: Lembaga Pengembangan Sarana Pengukuran dan Pendidikan Psikologi Fakultas Psikologi Universitas Indonesia.

Radden, J. (2014). Belief as delusional and delusion as belief. Philosophy, Psychiatry and Psychology, 21(1), 43-46. https://doi.org/10.1353/ppp.2014.0006

Ram, K. (2012). How is Afflictive Possession "Learned"? Gender and Motility in South India. Ethnos, 77(2), 203-226. https://doi.org/10.1080/00141844.2011.592952

Razali S.M. (1999). Dissociative trance disorder: a case report. Eastern Journal of Medicine, 4(2), 83-84.

Sanaz Ghasemi, Mohsen Kianpoor, Fatemeh Shahabizadeh, M. Y.-T. (2014). Frequency of Djinnati Syndrome among Inpatient Admissions at Baharan 
Psychiatric Hospital in Zahedan, Iran. Zahedan Journal of Research in Medical Sciences, 55-58.

Siswanto. (2007). Kesehatan Mental: Konsep, Cakupan dan Perkembangannya. Yogyakarta: Penerbit Andi.

Siswanto. (2015). Psikologi Kesehatan Mental: Awas Kesurupan! Yogyakarta: Penerbit Andi.

Smith, J. A. (1995). Semi-Structured Interviewing and Qualitative Analysis. In \& L. V. L. J. A. Smith, R. Harre (Ed.), Rethinking Methods In Psychology (pp. 9-26). London: Sage Publications.

Somer, E. (2006). Culture-bound dissociation: A comparative analysis. Psychiatric Clinics of North America, 29(1), 213-226. https://doi.org/10.1016/j.psc.2005.10.009

Strauss, A. L., \& Corbin, J. M. (1998). Basics of Qualitative Research: Techniques and Procedures for Developing Grounded Theory. Thousand Oaks, California: Sage Publications, Inc.

Uszkalo, K. C. (2012). Medical theories on malefic possession: From bewitchment to anti-NMDAR encephalitis. Journal of Religion in Europe, 5(3), 323-348. https://doi.org/10.1163/18748929-00503001

Vandenberg, B. (2012). Hypnosis and the pathologising of religious beliefs. Mental Health, Religion \& Culture, 15(2), 175-189. https://doi.org/10.1080/13674676.2011.566262

Walter, N.B. \& Fridman, E.J.N. (2004)). Shamanism: an encyclopedia of world beliefs, practices, and culture. Santa Barbara, California: ABC-CLIO, Inc.

Willig, C. (2008). Introducing Qualitative Research in Psychology: Adventures in The Theory and Method (Second edi). New York: Open University Press McGraw-Hill Education.

World Health Organization. (1992). ICD-10 The ICD-10 Classification of Mental and Behavioural Disorders: Clinical descriptions and diagnostic guidlines. Geneva: World Health Organization.

Yeong Ng, B., Keong Yap, A., Su, A., Lim, D., \& How Ong, S. (2002). Personality profiles of patients with dissociative trance disorder in Singapore. Comprehensive Psychiatry, 43(2), 121-126.

Yin, R. K. (2015). Studi Kasus: Desain \& Metode (M. D. Mudzakir, Ed.). Depok: PT Rajagrafindo Persada. 